\title{
ASPEK -ASPEK HUKUM PERJANJIAN INTERNASIONAL DAN KAITANNYA DENGAN MOU HELSINKI
}

\author{
Maryati B \\ Fakultas Hukum Universitas Abulyatama \\ Jl. Blang Bintang Lama Km 8,5 Lampoh Keude Aceh Besar, email: marunaya91@gmail.com
}

\begin{abstract}
Abstrak: MoU Helsinki 2005 adalah kesepakatan damai yang dibuat oleh subjek-subjek hukum internasional yaitu Negara (Indonesia) dan Pemberontak (GAM). Penelitian ini mengumpulkan data melalui studi kepustakaan untuk memperoleh data sekunder dan studi lapangan dengan melakukan wawancara dengan pihak-pihak yang terlibat untuk memperoleh data primer, kemudian data dianalisis dengan menggunakan metoda deskriptif analitis serta ditulis sebagai laporan dengan menggunakan pendekatan kualitatif. Dari hasil analisis data disimpulkan bahwa MoU Helsinki dilihat dari subjek yang mengadakannya (Negara RI dan Pemberontak GAM) dapat digolongkan sebagai bagian dari perjanjian internasional yang bersifat treaty contract yang hanya berlaku bagi mareka yang menyepakatinya saja (subjek-subjek pelaku). Mengingat sifat perjanjian bahwa MoU Helsinki sebagai kesepakatan atau perjanjian antara dua pihak berlaku syarat-syarat perjanjian bahwa para pihak tidak boleh dihilangkan, supaya perjanjian tidak berakhir dan tidak punah. Sementara itu, jika dilakukan pelanggaran dalam pelaksanaannya termasuk melanggar pasal-pasal turunan UU Pemerintah Aceh, maka pihak yang dirugikan dapat menuntut pelanggar dan dapat meminta ganti kerugian atau pemenuhan perjanjian yang dilanggar, yang tentu saja pelanggaran itu sangat berisiko bagi kelangsungan perdamaian di Aceh. Disarankan agar Pemerintah Pusat dapat melaksanakan isi MoU Helsinki atau UU Pemerintah Aceh yang belum terlaksana sesuai kesepakatan agar perdamaian di Aceh tetap utuh selamanya.
\end{abstract}

Kata Kunci : MoU Helsinki, Perjanjian Internasional, Perdamaian Permanen.

The Helsinki 2005 Memorandum of Understanding (MoU) is a peace agreement that was made by the international law subjects upon the agreement between the states (Indonesia) and the rebel group (Free Aceh Movement - GAM). However, there are some questions underlying this agreement. The first is whether the Helsinki MoU can be classified as an international agreement or not if it is viewed from the subjects who signed the agreement. The second issue is about the status of the parties who signed the $\mathrm{MoU}$; whether it can be eliminated according tothe agreement rules or not. The last issue is due to the law consequences ifthose parties break the agreement during the implementation of the MoU. This studyused a qualitative research method. The primary data was collected through interviews and the secondary data was obtained through the library research. The data was analyzed by using descriptive analytical method that was written in the form of report.From the data analysis it is found that the MoU Helsinki is categorized as an international agreement which use a treaty contract that only applies to the parties who sign the agreement. Considering of this agreement that is signed by only two parties which bound by the agreement rules; so, the parties must not be eliminated. This is done in order to keep the agreement to be still in place and not extinct. Further, it is also found that if the infraction happens during the implementation of the agreement i.e break the local laws (qanun) and its derivatives; then, the inflicted party can prosecute the offender into the trial. They also can request for a detriment or ask for the correct implementation of the agreement as it is agreed upon the agreement. If the infraction does occur, it will put the agreement at risk and harm the MoU. It is suggested that the Indonesian government should implement the MoU as it is already stated in the agreement and also bring about the qanun that has been made by both parties. This is done as the way to keep the peace agreement still in place.

Keywords : MoU Helsinki, International agreement, and Permanent agreement. 
Perjanjian Internasional adalah perjanjian yang dibuat oleh atau diadakan di antara subjeksubjek hukum Internasional, baik di antara negara dengan negara, maupun antara negara dengan subjek hukum internasional yang lain, atau diantara subjek hukum internasional bukan negara satu sama lain. Menurut Prof. Mochtar Kusumaatmadja, perjanjian Internasional adalah perjanjian yang diadakan antara anggota masyarakat bangsa-bangsa dan bertujuan untuk mengakibatkan akibat hukum tertentu (Mochtar Kusumaatmadja, Pengantar Hukum Internasional : hal. 84).

Perjanjian internasional juga memiliki banyak istilah, yakni treaty, convention, declaration, charter, protocol, pact, agreement, statute, covenant, dan lain-lain. Selama ini istilah-istilah tersebut terus digunakan sesuai dengan kedudukan dan tujuan perjanjian tersebut di tengah percaturan internasional yang bersifat publik. Namun, dipersoalkan bagaimanakah status sebuah perjanjian atau kesepakatan yang pelakunya subjek hukum internasional yang telah ditetapkan, apakah serta merta dapat digolongkan sebagai perjanjiaan internasional atau dengan sebutan istilah lainnya, diperlukan jawaban. Misalnya sebuah kesepakatan damai antara organisasi pemberontak dengan pemerintah negara induknya sendiri, seperti $\mathrm{MoU}$ Helsinki tahun 2005.

Penelitian ini membahas tentang $\mathrm{MoU}$ Helsinki 2005 dan Perjanjiann Internasional. MoU Helsinki adalah kesepakatan damai antara Republik Indonesia dan Gerakan Aceh Merdeka (GAM). Kesepakatan damai itu ditandatangani pada tanggal 15 Agustus tahun 2005 di Helsinki, Finlandia. Kalau dipertanyakan mengapa di Helsinki, adalah karena yang memfasilitasi perdamaian itu Consultatif Management Inisiative (CMI) yang dipimpin oleh mantan Presiden Finlandia, Martti Ahtisaari. Maarti Ahtisaari inilah kunci dari perdamaian Aceh setelah berperang hampir 30 tahun (4 Desember 1976 s/d 15 Agustus 2005).

GAM adalah organisasi pemberontak di Aceh yang dicetuskan oleh DR. Hasan Muhammad Ditiro dan diproklamirkan pada tanggal 4 Desember tahun 1976 di Gunung Halimon Pidie, sementara itu Aceh sejak tahun 1959 dikukuhkan sebagai salah satu propinsi di Indonesia. Pemberontakan ini merupakan reaksi atas kegagalan "Ikrar Lamteh", yang terjadi antara Pemerintah RI dengan DI/TII pada tahun 1957. Pemberontakan DI/TII itu sendiri di Aceh meletus sejak tahun 1953, menyusul pencabutan status propinsi untuk Aceh dan penggabungan Aceh dengan Propinsi Sumatera Utara.

Di dalam Hukum Internasional, Pemberontak (insurgency) dan Pihak Berperang (belligerency) merupakan salah satu subjek hukum internasional, disamping subjek hukum internasional lainnya, yakni Negara (sebagai subjek utama dan tertua), Organisasi Internasional, Tahta Suci (Vatikan), Palang Merah Internasional (ICRC) dan Individu.

Perjanjian damai itu merupakan produk hukum atau politik antara pemberontak dan negara. Negara merupakan subjek hukum internasional yang jika melakukan perjanjian dengan negara lain atau dengan organisasi 
internasional atau sebaliknya disebut dengan "Perjanjian Internasional" sebagaimana diatur Konvensi Wina 1969 Tentang Perjanjian Internasional.

Penelitian ini bertujuan untuk :

1. Membahas apakah MoU Helsinki 2005 dapat digolongkan sebagai bagian dari Hukum Perjanjian Internasional dilihat dari subjeknya.

2. Membahas apakah para pihak dalam kesepakatan damai atau MoU Helsinki 2005 tersebut dapat ditiadakan sesuai dengan aturan perjanjian.

3. Untuk mengetahui apa akibat hukum jika terjadi pelanggaran terhadap pelaksanaan atau realisasi MoU Helsinki 2005 sesuai dengan syaratsyarat perjanjian.

\section{METODE PENELITIAN}

Penelitian ini menggunakan Studi Kepustakaan (Library Research) dengan mengkaji buku-buku teks (literature) dan bahan informasi dari internet serta peraturan perundang-undangan, baik bersumber dari dalam negeri Indonesia dan dari dunia internasional sebagai bahan sekunder, disamping menginterview pihak tertentu yang terlibat atau memahami persoalan perdamaian Aceh dan MoU Helsinki 2005 sebagai bahan primair. Kemudian data atau bahan hukum tersebut dianalisis dan dengan menggunakan metoda deskriptif.

\section{HASIL DAN PEMBAHASAN}

\section{MoU Helsinki Sebagai Bagian dari Perjanjian Internasional}

MoU Helsinki Tahun 2005 tentang Kesepakatan Damai Republik Indonesia dan Gerakan Aceh Merdeka, dipertanyakan apakah merupakan bagian dari perjanjian internasional, dijawab melalui analisis politis dan analisis yuridis. Dilihat dari pendekatan politis, $\mathrm{MoU}$ itu memang sebuah produk politis, artinya kesepakatan dicapai dalam rangka menjalankan kepentingan politis pihak RI dalam rangka mencari penyelesaian damai konflik Aceh yang telah berjalan lama, sejak 4 Desember 1976. Konflik ini telah berlangsung dibawah 5 orang presiden RI (Suharto, BJ Habibie, Abdurrahman Wahid, Megawati Sukarno Putri, dan Susilo Bambang Yudhoyono). Di masa reformasi (1998) di bawah pemerintahan BJ Habibie, gerakan sipil Aceh yang telah dimulai sejak masa pemerintahan Suharto mengambil peran untuk menyelesaikan konflik Aceh secara damai. Di bawah presiden Abdurrahman Wahid (Gus Dur), rakyat Aceh kompak menggelar tuntutan "Referendum" pada tanggal 8 November 1999, yang digelar di depan Masjid Raya Baiturrahman Banda Aceh yang dihadiri lebih dari 500.000 rakyat Aceh. Inilah gelar aksi politik terbesar di Aceh sepanjang masa. Klaim dari pihak pelaksana referendum dan GAM itu dihadiri oleh 2 juta rakyat Aceh. Tapi pihak pemerintah RI mengklaim 500 ribu orang yang hadir. Akan tetapi berapapun jumlah yang hadir yang jelas referendum atau jajak pendapat itu rillnya didukung oleh lebih dari setengah rakyat Aceh. Ini artinya didukung oleh lebih dari 2 juta orang. Ini 
sebuah prestasi demokrasi super raksasa, yang seharusnya disahuti dan diselesaikan secara bijak. Tuntutan pelaksanaan referendum yang didukung oleh lebih setengah rakyat Aceh itu kemudian dijawab dengan perundingan damai, yang diantaranya mengalami kegagalan, yakni CoHA yang dfasilitasi HDC dari Swiss pada tahun 2003 pada Tokyo Meeting seperti telah disebutkan di depan.

Pasca tsunami super dahsyat di Aceh tanggal 26 Desember 2004, perundingan yang telah digagas lagi sebelum bencana datang, dimulai lagi. Gagasan dan pelaksanaan perundingan pasca tsunami berlangsung di Helsinki Finlandia dan difasilitasi oleh CMI sebagaimana telah disebutkan di depan. Perundingan kemudian berlangsung sebanyak 5 putaran sebelum akhirnya dicapai kesepakatan kedua belah pihak, Pemerintah RI dan GAM (baca Ahmad Farhan Hamid : Jalan Damai di Nanggro Endatu..., dari hal.167-213). Perundingan alot yang berlangsung selama tujuh setengah bulan ini, keberhasilannya memang sangat dipicu faktor tsunami. Akan tetapi faktor politik sangat dominan di dalamnya, sehingga MoU Helsinki ini layak disebut sebagai produk politik.

Berdasarkan hasil penelitian, MoU Helsinki itu punya hubungan erat dengan perjanjian internasional. Bukan hanya karena dirundingkan di luar negeri dan dimediasi oleh lembaga lembaga yang sering terlibat dalam perdamaian di berbagai negara (CMI) dan mediatornya adalah tokoh dunia bekas kepala negara asing, akan tetapi dalam konteks hubungan dengan perjanjian internasional, para pihak pada MoU Helsinki adalah subjek hukum internasional. Negara berdaulat sebagai salah satu pihak dan pemberontak serta pihak berperang sebagai pihak lawan berunding. Kedua belah pihak ini telah berulang kali disebut adalah subjek hukum internasional. Meskipun diakui paling belakangan sebagai subjek hukum internasional, akan tetapi Pemberontak dan Pihak berperang telah resmi diakui sebagai subjek hukum internasional disamping subjek hukum internasional yang lain (Baca Mochtar Kusumaatmadja: Pengantar Hukum Internasional). Mochtar Kusumaatmadja menggolongkan Pemberontak dan Pihak berperang sebagai subjek hukum internasional. Demikian juga halnya dengan JG Starke ahli hukum internasional tersohor di dunia, serta ahli hukum internasonal yang lain.

Penggolongan Pemberontak ke dalam subjek hukum internasional telah resmi diakui PBB. PBB bukan hanya mengakui Palestina Liberation Organization (PLO) sebagai pemberontak yang akan membebaskan Palestina dari cengkeraman Israel, akan tetapi juga mengakui pemberontak yang lain di berbagai belahan dunia. Apapun alasannya PBB telah mengakui Fretilin di Timor Leste sebagai pemberontak yang berjuang memerdekakan wilayahnya dari Indonesia, sehingga mengeluarkan Resolusi untuk mendukung perjuangan rakyat Timor Leste menentukan nasib sendiri. Dukungan PBB tentu saja karena kesepakatan PBB dalam menggolongkan Pemberontak sebagai subjek hukum internasional. Memang kasus Timor Leste juga karena kesalahan tindakan Indonesia yang mengintegrasikan Timor Leste sebagai propinsi ke27 Indonesia tanpa melalui proses jajak pendapat (referendum) dalam rangka menentukan nasib 
sendiri (apakah merdeka, bergabung dengan negara lain atau bergabung lagi dengan bekas negara penjajah). Timor Leste yang bekas wilayah jajahan Portugis, saat itu berada dalam proses perjuangan kemerdekaan setelah ditinggalkan Portugis. Akibatnya begitu Fretilin melakukan perlawanan, maka PBB mengeluarkan resolusi dan kemudian PBB menyelenggarakan jajak pendapat yang dimenangkan oleh $68 \%$ rakyat Timor Leste dan selebihnya memilih bergabung dengan Indonesia. Referendum yang dimonitor dan difasilitasi PBB ini tentu saja bermuara kepada lahirnya negara baru Timor Leste di tahun 1998.

Dari kasus Timor Leste dan kasus lain di dunia seperti Kemerdekaan Sudan Selatan, dimana kaum pemberontak diakui sebagai subjek hukum internasional sehingga mau tak mau produk hukum atau produk politik ini dianggap sebagai bagian dari perjanjian internasional terkait dengan subjeknya.

Kalau dipersoalkan peraturan apa yang mendasari atau dasar hukum dari perjanjian tersebut, mengingat perjanjian negara dengan negara atau perjanjian negara dengan organisasi internasional dan sebaliknya punya dasar hukum yaitu Konvensi Wina 1969, maka dunia punya dasar hukum tertua yang kerap digunakan sebelum konvensi itu lahir, yaitu asas "Pacta Sunt Servanda". Jadi, sebelum dasar hukum untuk itu ada, maka bisa digunakan asas Pacta Sunt Servanda tersebut.

\section{Akibat Hukum Pelanggaran Terhadap MoU}

\section{Helsinki 2005}

Sebagaimana telah dikupas di atas, bahwa pelanggaran suatu perjanjian internasional ataupun nasional membawa konsekuensi bagi para pihak. Pihak yang melakukan pelanggaran akan berhadapan dengan lawannya, apakah sang lawan akan menuntut ganti rugi atau menuntut dipenuhinya hak dan kewajiban yang menjadi terganggu oleh adanya pelanggaran tersebut, ataukah sampai kepada akibat lebih jauh berupa batalnya perjanjian. Atau paling tidak hilangnya kepercayaan pihak yang satu kepada pihak yang lain. Aceh pernah hilang kepercayaan kepada negara induknya Republik Indonesia ini karena persoalan pelanggaran perjanjian, yaitu "Ikrar Lamteh" sebagai ikrar damai untuk menghentikan permusuhan. Ikrar Lamteh yang dicetuskan tabggal 7 April tahun 1957 itu berbunyi : "Kami putra-putra Aceh, di pihak manapun berada akan berjuang bersungguh-sungguh untuk: Menjunjung tinggi kehormatan agama Islam, Menjunjung tinggi kehormatan dan kepentingan rakyat Aceh." (M Hamdan Basyar, dkk : Aceh Baru : Tantangan Perdamaian dan Reintegrasi, hal 10-11).

Berbeda dengan perjanjian damai Aceh, baik CoHA apalagi kesepakatan damai Helsinki. Perjanjian damai ini bukan hanya melibatkan pihak internasional sebagai mediator (Martti Ahtisaari dengan CMInya), akan tetapi perundingan yang berlangsung hingga 5 putaran itu juga dilangsungkan di luar negeri (Helsinki, Finlandia) dan melibatkan Uni Eropa dan perkumpulan negara di Asia Tenggara, ASEAN. Terlebih lagi bukan hanya dilangsungkan di luar negeri dan ditandatangni wakil dari pimpinan pucuk masingmasing pihak dan melibatkan negara-negara yang telah menjadi organisasi yang kat seperti Uni Eropa dan ASEAN, akan tetapi kesepakatan itu juga berisi klausul yang sangat menarik dan luar 
biasa, yang menguntungkan kedua belah pihak. Bagi pihak RI persoalan penanganan keamanan dengan decommisioning, bagi pihak GAM dengan pemberian amnesti menyeluruh bagi yang terlibat dalam gerakan, baik sebagai kombatan maupun peserta gerakan politik saja. Bagi rakyat Aceh apa yang paling menguntungkan adalah adanya janjijanji di bidang politik dan ekonomi. Janji politik berupa pemilihan independen dan partai lokal serta fasilitas lain.

Dibidang ekonomi yang paling menonjol adalah adanya kesepakatan bagi hasil terhadap sumber daya alam hidro karbon dengan pembagian 70 persen untuk Aceh dan 30 persen untuk Pemerintah Pusat. Pada hal dimasa sebelumnya Aceh hanya menerima 0,5 persen dari hasil pengeboran Minyak dan Gas di bumi Aceh.

Kesepakatan di bidang HAM juga luar biasa, yaitu Aceh berhasil mendorong diratifikasinya dua dari The International Bill Of Human Rights : Internatinal Covenant on Civil and Political Rights 1966 dan International Covenant on Economical, Social and Cultural Rights 1966, masing dengan UU No. 12 tahun 2005 dan UU N0. 11 Tahun 2005. Bukan Cuma itu, Pengadilan HAM juga disepakati digelar untuk Aceh dan Komisi Kebenaran dan Rekonsiliasi (KKR) dan Komisi Penyelesaian Klaim juga disepakati dibentuk di Aceh. Selain itu juga terdapat berbagai klausul lain yang menunjukkan adanya keistimewaan untuk Aceh sehingga jika semua itu diimplementasikan Aceh menjadi sebuah wilayah dengan "Self Government" atau Pemerintahan Sendiri, sebagaimana telah dipraktekkan di berbagai negara.

Istimewanya, semua butir-butir kesepakatan itu telah tertuang dalam UU Pemerintah Aceh, UU No. 11 Tahun 2006 yang dirancang oleh masyarakat sipil, politisi Aceh (DPRD) dan GAM untuk kemudian dibahas di Jakarta (DPR RI) sebelum disahkan. Namun, baru tahap pembahasan UU saja telah mengalami penyimpangan dari amanat MoU Helsinki 2005, yakni dengan adanya klausul harus terikatnya ketentuan undang-undang ini dengan standar dan prosedur peraturan perundangan nasional.

Hingga saat ini UU Pemerintah Aceh telah diberlakukan selama 10 tahun, akan tetapi apakah semua isi pasal telah ada peraturan pelaksananya dan telah dilaksanakan sebagaimana mestinya? PP Migas dan PP Kewenangan Aceh yang sangat alot pembahasannya apakah telah mengakomodir butirbutir MoU Helsinki dan UU Pemerintah Aceh? Yang jelas PP itu telah disahkan dan dilaksanakan. Di samping ada yang belum ada realisasinya

Yang menjadi persoalan bagi penelitian ini adalah bagaimana kalau kesepakatan (MoU Helsinki) itu dilanggar. Telah dipaparkan apa saja kesepakatan penting yang berhasil dicapai dalam kesepakatan. Kalau dilihat pada isi kesepakatan, bagian 6 tentang Penyelesaian Perselisihan, terlebih dulu harus ditarik asumsi bahwa adanya perselisihan apabila ada pelanggaran terhadap kesepakatan damai tersebut. Pelanggaran bukan hanya dilakukan salah satu pihak, akan tetapi kedua belah pihak dapat melakukannya. Inilah poin-poin penyelesaian perselisihan :

1. Perselisihan yang terjadi atas pelaksanaan MoU akan diselesaikan oleh Kepala Misi Monitoring, melalui musyawarah dengan para pihak dan semua pihak memberikan informasi yang dibutuhkan secepatnya. 
Kepala Misi Monitoring akan mengambil keputusan yang akan mengikat para pihak.

2. Jika Kepala Misi Monitoring menyimpulkan bahwa perselisihan tidak dapat diselesaikan dengan cara sebagaimana tersebut di atas, maka perselisihan akan dbahas bersama oleh Kepala Misi Monitoring dengan wakil senior dari setiap pihak. Kepala Misi Monitoring akan mengambil keputusan yang akan mengikat para pihak.

3. Dalam kasus-kasus di mana perselisihan tidak dapat diselesaikan melalui salah satu cara sebagaimana disebutkan di atas, Kepala Misi Monitoring akan melaporkan secara langsung kepada Mentri Koordinator Politik Hukum dan Keamanan Republik Indonesia, pimpinan politik GAM dan Ketua Dewan Direktur Crisis Management Initiative, serta memberitahu Komite Politik dan Keamanan Uni Eropa. Setelah berkonsultasi dengan para pihak, Ketua Dewan Direktur Crisis Management Initiative akan mengambil keputusan yang mengikat para pihak.

Berdasarkan aturan penyelesaian di atas, maka yang punya otoritas menyesaikan sengketa ada dua, pada tahap pertama Ketua Misi Monitoring sebagai pengambil keputusan dengan pelibatan para pihak, dan pada tahap kedua jika tahap pertama gagal adalah Ketua Dewan Direktur CMI juga sebagai pengambil keputusan dengan melibatkan pimpinan politik kedua belah pihak serta komite politik dan keamanan Uni Eropa. Itulah peraturan $\mathrm{MoU}$ Helsinki. Karena tidak ada perselisihan yang berarti pada awalnya.aka propses itupun tidak terjadi.
Ada beberapa hal atau penyebab suatu bprjanjian dikatakan telah mengalami pelanggaran, yaitu : Tidak melakukan apa yang disanggupi dilakukan, melaksanakan apa yang diperjanjikan tetapi tidak sebagaimana diperjanjikan, melakukan apa yang diperjanjikan tetapi terlambat, melakukan sesuatu yang menurut perjanjian tidak boleh dilakukan.

Jika pelanggaran dilakukan saat ini, umpamanya tidak dibentuk KKR, Komisi Penyelesaian Klaim, Pengadilan HAM, tidak dilaksanakan bagi hasil migas $70 \%$ untuk Aceh dan $30 \%$ untuk Pusat, tidak diindahkannya butirbutir MoU lain yang telah dituang dalam UUPA atau yang tidak dituang, sudah pasti akan terjadi perselisihan. Atau jika KKR yang sudah terbentuk itu tidak dapat bekerja sebagaimana mestinya, atau bahkan Komisi Klaim dan Pengadilan HAM tidak dapat terbentuk atau jika nanti terbentuk tapi tidak dapat melaksanakan tugasnya karena dihadang kepentingan politik, dll, lantas bagaimana menyelesaikan pelanggaran. Inilah pelanggaran menurut katagori "tidak melakukan apa yang disanggupi dilakukan dan/atau melaksanakan apa yang diperjanjikan tapi tidak sebagaimana diperjanjikan". Jika hal ini terjadi berarti telah terjadi pelanggaran serius.

Apabila pelanggaran seperti disebut di atas terjadi masihkah Misi Monitoring ada? Kalau Misi Monitoring itu tak ada, apakah Direktur Eksekutif CMI masih berfungsi? Pemerintah Pusat dengan segala daya dan taktik menghindari terjadinya perselisihan. Kemudian dipihak GAM atau Aceh, kalaupun terjadi penekanan atau pembiasan implementasi pasal-pasal UUUPA ke dalam Peraturan Pelaksana lebih banyak berdiam diri. 
Berbeda dengan masa awal tercapainya perdamaian, di mana tingkat kritis masih tinggi, saat ini setelah masa berlalu 10 tahun, menggerakkan massa untuk mengawal proses politik dan hukum sudah tidak mudah. Apakah karena masyarakat terutama kaum muda mahasiswa sudah apatis atau sudah lelah.

Kalau terjadi sengketa karena salah satu pihak melanggar ketentuan kesepakatan atau mengabaikan isi pasal UUPA yang telah disepakati apakah dalam mengeluarkan PP atau melaksanakan isi UU, mungkinkah Direktur Eksecutive CMI masih mau turun tangan. Kalau dicari solusi lain lantas apa solusinya? Apakah kembali kepada ketentuan hukum perjanjian yang ada bahwa kalau salah satu pihak melakukan pelanggaran maka pihak lain dapat menuntut ganti kerugian, apakah hal itu dapat berlaku.

Semestinya kalau kita kembali kepada ketentuan Hukum Perjanjian, jika salah satu pihak wanpestasi, maka pihak lain dapat menuntut ganti kerugian atau dilaksakan prestasi sebagaimana mestinya. Apakah untuk kesepakatan sejenis MoU Helsinki ini tuntutan terhadap pelaksanaan prestasi yang terkendala atau yang sengaja tidak atau terlambat dipenuhi dapat berjalan efektif, mengingat janji-janji yang adalah hukum ini memiliki tendensi politik yang tinggi. Namun secara moral dan fungsi hukum yang seharusnya berjalan yang betdasarkan pada adagium Pacta Sunt Servanda serta ajaran Islam tentang mengikatnya sebuah janji sesuai hadis Nabi Muhammad SAW bahwa mengingkari janji adalah tanda-tanda munafiqin, menjadi tameng dari kesepakatan damai tersebut. Apalagi rakyat Aceh telah lelah berkonflik, sehingga menjawab persoalan politik tidak mungkin lagi dengan mengangkat senjata seperti di masa lalu, melainkan harus diselesaikan secara hukum dan moral serta panduan agama demi tegaknya perdamaian permanen yang hakiki.

\section{KESIMPULAN DAN SARAN}

\section{Kesimpulan}

1. Jika dilihat dari subjek hukum yang mengadakannya atau yang merundingkannya atau menyepakati dan menandatanganinya maka MoU Helsinki, kesepakatan damai Republik Indonesia dan Gerakan Aceh Merdeka (GAM) tahun 2005 dapat digolongkan sebagai bagian dari "Perjanjian Internasional," karena para pihaknya adalah subjek hukum internasional, bukan karena difasilitasi oleh pihak luar negeri serta dimonitor oleh Uni Eropa. Namun kesepakatan ini hanyalah kesepakatan yang berbentuk "Treaty Contract', yang berlaku terbatas bagi pihak yang mengadakannya saja dan dasar dari kesepakatan itu adalah "Pacta Sunt Servanda" sebagai ajaran moral.

2. Status para pihak pada kesepakatan damai (MoU Helsinki) 2005 itu harus permanen, di mana pihak-pihak yang mengadakan secara logika dan hukum harus tetap berfungsi sebagai para pihak, atau salah satu pihak tidak boleh dibubarkan (dalam hal ini pihak GAM), sebab jika salah satu pihak dibubarkan maka kesepakatan atau perjanjian akan memenuhi syarat"batal." Jika perjanjian damai batal maka perdamaianpun tidak jelas lagi nasibnya. 
3. Akibat hukum jika dilakukan pelanggaran terhadap kesepakatan damai RI-GAM (MoU Helsinki), sesuai kesepakatan secara alamiah akan terjadi perselisihan di antara para pihak. Maka penyelesaian yang dapat ditempuh adalah sesuai pengaturan MoU Helsinki itu sendiri, yakni diselesikan oleh pihak Misi Monitoring atau kalau tidak tercapai hasil diselesaikan oleh Direktur Eksecutif CMI. Tentu saja kalau lembaga-lembaga itu telah tidak berpartisipasi dapat diselesaikan sesuai asas "Pacta Sunt Serpanda" atau sesuai ketentuan hukum perjanjian, yakni tuntutan ganti kerugian oleh pihak yang dirugikan.

\section{Saran-Saran}

1. Disarankan kepada para pihak agar tetap mematuhi apa yang telah diperjanjikan atau disepakati dalam perjanjian damai $\mathrm{MoU}$ Helsinki dan implementasi UUPA agar keseimbangan atau kedamaian yang telah diperoleh tidak mengalami kegoncangan. Pemenuhan ini adalah dengan adanya sikap saling menghargai dan menghormati, menjauhkan penegakan hegemoni, serta menegakkan demokrasi secara adil dan bermartabat.

2. MoU Helsinki harus dijadikan sebagai dasar dari penyelesaian konflik dan sebagai harga diri bagi rakyat Aceh sepanjang masa.

3. MoU Helsinki adalah produk kesepakatan bermartabat, oleh karena itu jangan pernah ada yang menyepelekannya, bukan hanya karena telah menjadi dasar dari penyusunan UU Pemerintah Aceh, akan tetapi yang lebih penting adalah karena dunia telah terlibat di dalamnya (Uni Eropa dan ASEAN) dan telah pernah memberi apresiasi atas keberhasilannya, sehingga kepercayaan itu harus tetap dipertahankan.

\section{DAFTAR PUSTAKA}

Abdul Kadir Muhammad. (1986). Hukum Perjanjian, Bandung: Alumni.

Ahmad Farhan Hamid. (2006). Jalan Damai Nanggroe Endatu : Catatan Seorang Wakil Rakyat Aceh, Jakarta: Suara Bebas.

Al Chaidar. (1999). Gerakan Aceh Merdeka, Jihad Rakyat Aceh Mewujudkan Negara Islam. Jakarta: Madani Press.

Amiruddin, dkk. (2017). Aceh Meniti Transisi, Draft Scenario Aceh Masa Depan (2007-2017). Yayasan Tifa-ACSTF.

Bob Sugeng Hadiwinata, dkk. (2010). Transformasi Gerakan Aceh Merdeka dari Kotak Peluru ke Kotak Suara, Sebuah Kisah Sukses Program Transformasi Kombatan di Aceh, Jakarta: Friederich Ebert Stiftung (FES).

Boer Mauna. (1987). Hukum Internasional, Jakarta: Pusat Pendidikan dan Latihan Departemen Luar Negeri.

Budi Lazarusli-Syahmin AK. (1986). Suksesi Negara dalam Hubungannya dengan Perjanjian Internasional, Bandung: Remadja Karya.

Chairul Fahmi (2011). Aceh Pasca MoU Helsinki, Diskursus Tentang KKR, Reformasi Keamanan, dan Reformasi 
Hukum, Banda Aceh: Aceh Institute Press.

Hamdan Basyar, M, dkk. (2008). Aceh Baru: Tantangan Perdamaian dan Reintegrasi. Jakarta: Pustaka Pelajar-P2P LIPI.

Ikrar Nusa Bhakti. (2008). Beranda Perdamaian, Aceh Tiga Tahun Pasca MoU Helsinki. Jakarta: Pustaka Pelajar Pusat Penelitian Politik LIPI.

Mariam Darus Badrulzaman. (1994). Aneka Hukum Bisnis. Bandung: Alumni.

Maryati B. (2016). Penegakan Hukum dan HAM Terkait Implementasi MoU Helsinki Setelah Sepuluh Tahun Perdamaian Aceh. Jurnal Tasimak, 8 (2) Moch. Nurhasim, dkk.(2003). Konflik Aceh, Analisis atas Sebab-Sebab Konflik, Aktor Koflik, Kepentingan dan Upaya Penyelesaian. Jakarta: LIPI.

Mochtar Kusumatmaja. (1976). Pengantar Hukum Internasional, buku I Bagian Umum, Jakarta: Putra Bardin.

Munir Fuadi. (1997). Hukum Bisnis Dalam Teori dan Praktek, Buku Keempat. Bandung: Citra Adytia Bhakti.

Muslim Ibrahim, dkk. (2010). MoU Helsinki Dalam Bingkai Islam, Banda Aceh: Badan Reintegrsi Aceh.

Otto Nathan dan Heinz Norden. (2007). Einstein Bicara Perdamaian. Yogyakarta: Gala Ilmu Semesta.

Otto Syamsudin Ishak. (2008). Perdamaian, Yang Berikhtiar, yang Menentang, Kronik Perundingan GAM-RI di Helsinki 2005. Banda Aceh: ACSTF.
Starke, J.G. (1992). Pengantar Hukum Internasional (Edisi Kesepuluh). Penerjemah: Bambang Iriana Djajaatmadja, Jakarta: Sinar Grafika.

Subekti. (1983). Hukum Perjanjian (Cetakan VII). Jakarta: PT Intermasa.

Sumaryo Suryokusumo. (1990). Hukum Organisasi Internasional. Jakarta: UIPress.

Syahmin, AK. (1985). Hukum Perjanjian Internasional (Menurut Konvensi Wina 1969). Bandung: Armico.

Yusra Habib Abdul Gani. (2009). SelfGovernment, Studi Perbandingan Tentang Desain Administrasi Negara, Jakarta: Paramedia Press. 